\title{
DEVELOPMENT OF A PNEUMATIC OLIVE HARVESTER
}

\author{
Mohamed Ghonimy ${ }^{1,2}$, Mohamed Ibrahim ${ }^{1}$, Abdelfatah Drees ${ }^{3}$, Samy Marey $^{4 *, 5}$
}

\author{
${ }^{4 *}$ Corresponding author. Sciences, Technology and Innovation Unit, King Saud University, Riyadh, Saudi Arabia. \\ E-mail: samarey@ksu.edu.sa | ORCID ID: https://orcid.org/0000-0002-0261-2110
}

\section{KEYWORDS}

olive, pneumatic, hand-held, harvester, fruit removal, chemical abscission.

\begin{abstract}
A pneumatic olive harvester was developed and evaluated in this study. The components of the developed machine were the limb clamp, vibrating unit, control elements, main tube, air-pressured hoses, control valve, and power source. The measurements that related to the development of the harvester were fruit and limb damage, and some physical and mechanical properties of the olives fruit-stem system. The results demonstrated that the effectiveness of the developed machine to harvest olive fruits. The appropriateness of the developed machine was evaluated by some criteria: machine productivity, fruit removal, fruit damage, limb damage depth at the contact point with the clamp of the machine, breakage of shaken limb, and consumed energy. The suitable values of these criteria were achieved at $27 \mathrm{~Hz}$ frequency and $60 \mathrm{~mm}$ stroke.
\end{abstract}

\section{INTRODUCTION}

Olives tree is an evergreen tree that has been known for more than 3000 years. Originally, it was found growing in the geographical areas surrounding the Mediterranean Sea. The number of olive trees in the world is currently estimated at more than 865 million distributed all over the world, of which 95\% are located in the Mediterranean region (FAOSTAT, 2018). The Olive crop is considered one of the main crops all over the world, especially in the newly reclaimed areas. Most olive harvesting involves traditional methods, and the fruits are picked mostly by hand, picking the fruits individually, or beating the tree limbs with a pole, which causes them to fall. Canvases or nets are placed under the tree to collect the fallen fruits. However, this type of harvesting is time-consuming and involves intensive labor. Moreover, it results in a high level of fruit damage. Approximately 50\%-60\% of the total labor requirement is used for harvesting operations (Sessiz \& Ozcan, 2006). The mechanical harvesting of olives is performed either by shaking or combing the tree (Nasini \& Proietti, 2014). The producers prefer shaking over combing, as shaking causes less damage to the tree .Numerous sources can be used to power the harvesting equipment, including thermal engines (Diesel, Gasoline), electric motors, tractors, compressed air (pneumatic) and selfpropelled equipment (Sibbett et al., 2005). Pneumatic machines avoid problems of excessive loads, unlike electrical machine (Nasini \& Proietti, 2014). In addition, pneumatic systems are inexpensive, clean, safe, sensitive to vibrations, and easy to operate. The most factor that affect the olive mechanical harvesting is the ratio of fruit detaching force to the fruit mass (Almeidaa et al., 2015). To reduce the detachment force and facilitate the harvesting operation, chemical abscissions have been applied (Peterson et al., 2003). Hand-held harvesters are one of the important major methods employed in olive harvesting. These machines are characterized by fast performance compared to manual harvesting and reduced costs. Nevertheless, they do cause some damage by shaking branches and harvested fruits. Several researches were done to determine the optimum operating parameters of handheld olive harvesters (Sola-Guirado et al., 2016; Alzoheiry et al. 2020; Ghonimy et al. 2020). Ibrahim (2018) found that the most suitable operating conditions of the hand-held olive harvesting machine were at a pitting head speed of 1100-1500 rpm with 17-cm head length. Under these conditions, the fruit removal, machine productivity, and fruit damage were $97.7 \%, 91.5 \mathrm{~kg} / \mathrm{h}$, and $6.23 \%$

\footnotetext{
${ }^{1}$ Department of Agricultural Engineering, Faculty of Agriculture, Cairo University, Giza, Egypt.

${ }^{2}$ Department of Plant Production and Protection, College of Agriculture and Veterinary Medicine, Qassim University, Buraydah, Saudi Arabia.

${ }^{3}$ Faculty of Agriculture Engineering, Al-Azher University, Assuit, Egypt.

${ }^{5}$ Agricultural Engineering Research Institute (AENRI), Agricultural Research Centre, Giza, Egypt.
}

Area Editor: João Paulo Arantes Rodrigues da Cunha

Received in: 12-19-2019

Accepted in: 3-17-2021 
respectively. Younis et al. (2017) reported that the highest hand-held harvesting productivity was achieved at 1600 rpm and 3-min shaking period, whereas the least damage was reported at $900 \mathrm{rpm}$ and $3 \mathrm{~min}$, with the Kornaki variety. Zhou et al. (2014) found that the overall fruit removal efficiency of sweet cherry was $84 \%$ when the branches were shaken at the lowest excitation position, and the removal efficiencies dropped to $77 \%$ and $51 \%$, and subsequently rose to $72 \%$ as the excitation position moved up the limbs. The fruit damage rates from low to high excitation positions were $20 \%, 28 \%, 20 \%$, and $23 \%$, which was approximately $10 \%$ higher than those of handpicked fruit. Khdair et al. (2018) found that the productivity of pneumatic comb and branch shaker machines increased by two and four times compared to the traditional method (manual harvesting), respectively. Further, the fruit detachment force (FDF) was reduced from $9.35 \mathrm{~N}$ to 5.65 $\mathrm{N}$ for the 'Nabali Rosie' olive variety at the Ethrel level of $3000 \mathrm{mg} \mathrm{L}^{-1}$. Sessiz \& Ozcan (2006) reported that the olives removal percentage using a pneumatic shaker for harvesting without chemical application was lower than 50\%. The smallest fruit detachment force and the highest fruit removal (96\%) were obtained by employing a frequency of $24 \mathrm{~Hz}$ and a $12.5 \mathrm{ml} \mathrm{l}^{-1}$ concentration of abscission chemical at a constant amplitude of $60 \mathrm{~mm}$. In Egypt, the economic situation of the small-scale farms owners does not allow possession of olive fruits harvesting machines. Therefore, the aim of this study is to use the available low cost local materials in manufacturing a pneumatic olive fruits harvester and determine its optimum operation conditions.

\section{MATERIAL AND METHODS}

A pneumatic olive harvester was developed, manufactured, and evaluated to harvest the olive fruits. This study was realized through five stages: (i) determination of the physical and mechanical properties of the olive fruitstem system, (ii) development of the pneumatic olive harvester, (iii) determination of the effective range of the operational parameters, (iv) evaluation of the developed harvester, and (v) evaluate-the effect of chemical abscission on the mechanical harvesting performance.

\section{Plant parameters}

\section{Olive trees dimensions}

This measurement was conducted on fifteen-yearold olive trees (Shemlali variety) at Siwa Oasis, Egypt. Trees were planted at $6 \mathrm{~m}$ intervals between rows and $6 \mathrm{~m}$ intervals within rows $\left(278\right.$ trees ha $\left.^{-1}\right)$. The trees were trained to a modified central leader system. The olive trees were harvested at the appropriate harvesting stage (i.e., 21-25 weeks after full bloom). Fifteen olive trees were randomly selected. The dimensional characteristics of the selected olive trees were measured and reported in Table (1).

TABLE 1. Mean dimensions of Shemlali olive trees and branches.

\begin{tabular}{ll}
\hline Parameter & Length \\
\hline Tree height, $\mathrm{m}$ & $3.05 \pm 0.32$ \\
Trunk height, $\mathrm{m}$ & $0.8 \pm 0.06$ \\
Limb diameter, mm: & \\
\hline 10\% limb length & $61.6 \pm 4.0$ \\
20\% limb length & $56.0 \pm 3.1$ \\
30\% limb length & $44.3 \pm 3.2$ \\
40\% limb length & $34.1 \pm 2.3$ \\
50\% limb length & $29.9 \pm 4.1$ \\
\hline
\end{tabular}

\section{Apparent stiffness of olive limbs (K)}

Fifteen branches with a $36 \mathrm{~mm}$ mean diameter were randomly selected to measure the maximum branch deflection $(\delta)$ occurring at a load $\left(N_{l}\right)$, the apparent branch stiffness $(K)$ is determined using Equation 1. For this purpose, the tree trunk was supported, a leveling rod was fixed vertically, and the initial position of the branch was marked on the vertical leveling rod (Fig. 1). A spring balance scale was hanged in the branch at a distance of $40 \%$ of the branch length, as recommended by Erdoğan et al. (2003). The load was applied gradually at increment of 2 $\mathrm{kg}$, and the corresponding deflection $\cong$ vertical displacement) of the branch was recorded on the leveling rod. The experimental results showed that the average $K$ value was $3166 \mathrm{~N} \mathrm{~m}^{-1}$.

$$
K=N_{l} / \delta
$$




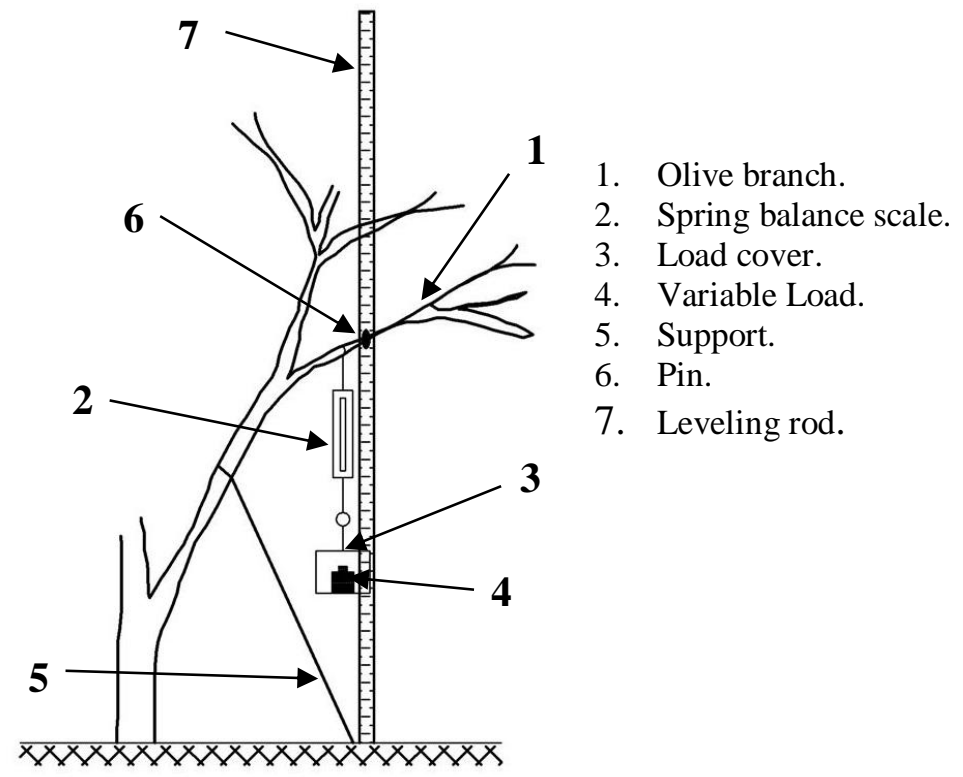

FIGURE 1. Schematic diagram of loading procedure.

\section{Physical and mechanical properties of olives fruit-stem system}

Shemlali olive fruits were classified visually into three groups according to their maturity levels based on fruit skin and flesh color according to maturity index described by Guzmán et al. (2013). The selected maturity levels were as follows: a) Full mature stage (skin color of the fruit was yellow-green), b) Half-ripe fruits (more than half of the fruit skin color was turned red, purple or black), and c) Full-ripe fruits (all fruit skin color was purple or black with all the flesh purple to the pit). For each maturity level, a sample of 100 olive fruits was collected randomly to measure their physical and mechanical properties. These properties included fruit length, fruit diameter, fruit mass, bulk density, stem length, and effective firmness. Both of fruit length, fruit diameter, and stem length were measured using a digital vernier caliper with accuracy of $\pm 0.1 \mathrm{~mm}$. Olive fruit mass was determined using a digital balance with an accuracy of \pm 0 . $1 \mathrm{~g}$. The bulk density of olive fruit was calculated by determining the mass of the fruit and its volume using volumetric calibration. The effective firmness was measured using FR-5120 digital fruit firmness tester (Accuracy of $\pm 0.5 \%+2$ digits). The ratio of the fruit detaching force to the fruit mass, $R_{F m}\left(\mathrm{~N} \mathrm{~g}^{-1}\right)$, is used to determine the suitability of the olive fruit for mechanical harvesting. The fruit detachment force was measured using a digital force gauge with $50 \mathrm{~N}$ capacity and accuracy of \pm $0.01 \mathrm{~N}$. The digital force gauge was attached to a selected fruit, and a pulling hand-force was applied and gradually enhanced until the fruit was separated. The maximum force was recorded as the static detachment force. Each detached fruit was subsequently weighed. The ratio $\left(R_{F m}\right)$ was calculated as follows:

$$
R_{F m}=\frac{F_{d}}{m_{f}}
$$

Where:

$F_{\mathrm{d}}$ represents the fruit detaching force $(\mathrm{N})$, and $m_{\mathrm{f}}$ is the fruit mass $(\mathrm{g})$.

\section{Development considerations}

The development of the pneumatic olive harvester has to be based on some important considerations such as: (i) being light weighted, (ii) being easy to operate and maintain, (iii) simple construction with low fabrication costs by utilizing simple components and locally available materials, and (iv) reduce the mechanical damage of branches during and after operations.

\section{The components of the developed harvester}

A pneumatic branch-shaker was manufactured, powered by a gasoline engine. The basic function of the branch-shaker is to convert the force of the pressurized air into a rotational motion, and subsequently to a reciprocating motion that is used to shake the olive tree branch. The main components of the shaker comprised the limb clamp, vibrating unit, main tube, air-pressured hoses, control elements, and the power source.

\section{Limb clamp}

The limb clamp (Fig. 2) consists of two parts of steel. One of them is fixed and links with the main tube by screw bolt. The second part shall be fixed to the first part so that the distance between the two parts ranged from 30 to 70 $\mathrm{mm}$. The inside face of the clamp is covered with a layer of sponge which is covered with a layer of leather. The two interior parts of the clamp is called pad. The function of the pad system is to transmit shaking force from the shaker to the tree branch and to distribute the shaking and clamping force over a layer area to minimize stresses in the contact area.

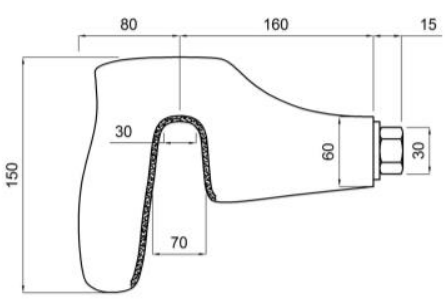

FIGURE 2. Sketch of limb clamp. 


\section{Vibrating unit}

A slider-crank mechanism was constructed to provide the shaking motion. The vibrating unit (Fig. 3) consists of three main parts:

(a)

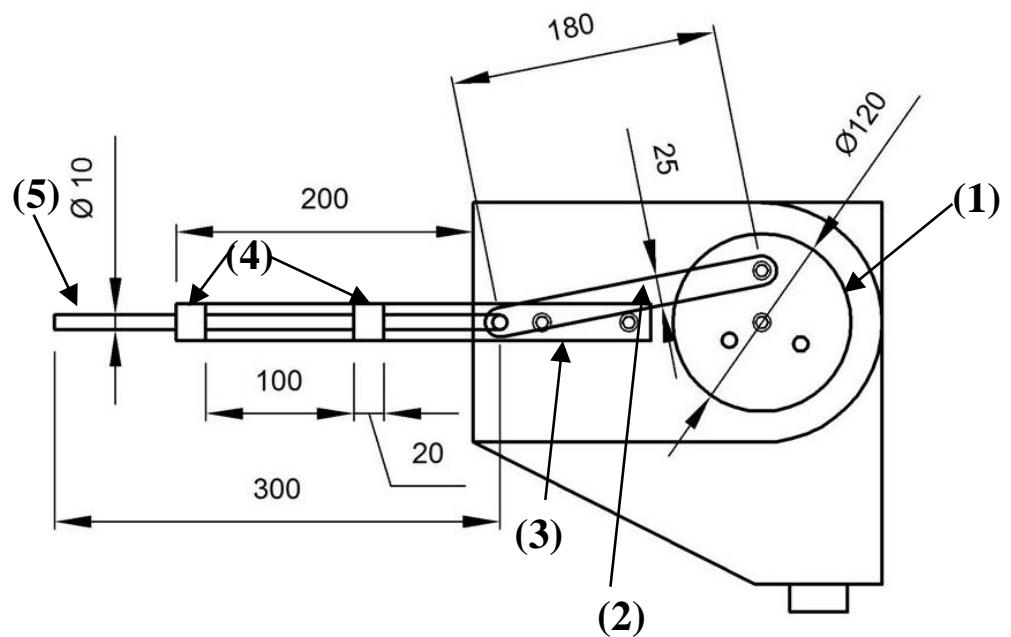

Dimensions in $\mathrm{mm}$

(b)

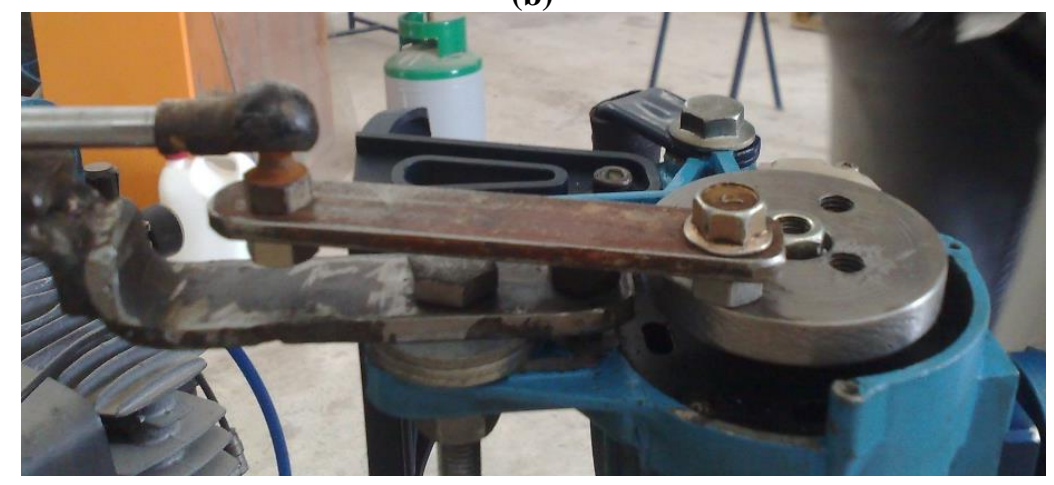

FIGURE 3. (a) Diagram of vibrating unit: (1) circular disk, (2) transmission arm, (3) supporting rod, (4) sleeve, and (5) vibrating rod; dimensions are given in $\mathrm{mm}$. (b) Photograph of vibrating unit.

The first part consists of a circular disk of $120 \mathrm{~mm}$ diameter, $20 \mathrm{~mm}$ thickness with three holes. The locations of these holes in the disk serve to select and adjust the proper stroke $(50,60$, and $70 \mathrm{~mm})$ as recommended by (Aiello et al., 2019). The second part consists of a connecting arm (200 mm length, $25 \mathrm{~mm}$ width, and $10 \mathrm{~mm}$ thick) to convert the rotational motion of the circular disk to a reciprocating motion of the limb clamp and subsequently to the tree branch. The third part is a vibrating rod $(300 \mathrm{~mm}$ length, $10 \mathrm{~mm}$ diameter), which transmits the reciprocating motion from the connecting arm to the limb clamp.

\section{Pneumatic motor}

A pneumatic motor was used to convert pneumatic energy into mechanical energy (i.e., the reciprocating motion produced by the vibrating unit). A flow control valve was employed to adjust the shaking frequency.

\section{Compressed air transmission tube}

A steel tube (2000 mm length, $20 \mathrm{~mm}$ diameter, and $2.5 \mathrm{~mm}$ thickness) was used to convey the pressurized air from the air compressor tank to the pneumatic motor (Fig. 4). A control valve was connected to the tube to regulate the air flow rate.

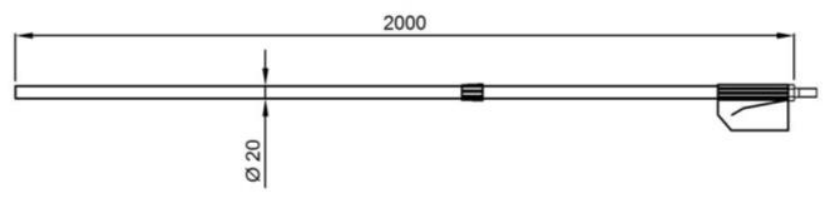

FIGURE 4. Compressed air conveyor tube; dimensions given in $\mathrm{mm}$.

\section{Hoses, valves, and pressure gauges}

Air pressure hoses made from synthetic rubber of 8 $\mathrm{mm}$ inner diameter were used, with a maximum working pressure of 20 bar. An air pressure regulator was used to maintain the air pressure at 8 bar during the operation, and air pressure gauge was used to indicate the air pressure in the shaking system.

\section{Power source}

The motion of the olive branch is in fact extensively complex. It has a non-uniform biological structure, which has an infinite number of degrees of freedom. Therefore, the branch system was analyzed as a single degree of freedom, and the branch was considered as a stiffness member with internal damping. To estimate the required power to operate 
the harvester, the following parameters are required for the olive branches: (i) average value of branch apparent stiffness $(K)$, (ii) average value of branch damping ratio $(\varepsilon)$, (iii) olives branch natural frequency $\left(\omega_{n}\right)$, and (iv) the displacement lags impressed force (Phase angle, $\alpha$ ). The apparent stiffness $(K)$ of the olive branches was estimated using [eq. (1)], yielding an average value of $3.166 \mathrm{kN} \mathrm{m}^{-1}$. The concept of free vibration decay was used to measure the internal damping ratio of the olive branch, which can be expressed as the logarithm of two successive oscillation amplitudes $\left(X_{1}, X_{2}\right)$. The damping ratio $(\varepsilon)$ was calculated according to Rao (2011) by:

$$
\varepsilon=\frac{1}{2 \pi(n-1)} \ln \frac{X_{1}}{X_{n}}
$$

Branches with fresh fruits were selected for this purpose; each branch was clamped to a massive steel support to eliminate any energy dissipation at the support, and the branch was subsequently manually displaced and released. This makes the branch vibrate at its natural frequency. By recording the change of oscillation amplitudes, and applying [eq. (3)], the average damping ratio $(\varepsilon)$ was estimated to be 0.168 . The natural frequency $\left(\omega_{\mathrm{n}}\right)$, in $\mathrm{Hz}$, of the olive branches was calculated from [eq. (4)] according to Rao (2011) as:

$$
\omega_{n}^{2}=\frac{K}{m}\left(1+\varepsilon^{2}\right)
$$

Where:

$K$ is the apparent stiffness $\left(=3166 \mathrm{~N} \mathrm{~m}^{-1}\right)$;

$m$ is the mass of unbalance (i.e., mass of the circular disk in Fig. 1, = $0.83 \mathrm{~kg}$ ), and

$\varepsilon$ is the damping ratio (0.168). Accordingly, the natural frequency $\left(\omega_{\mathrm{n}}\right)$ of the olive branch was estimated to be $62.6 \mathrm{~Hz}$.

The phase angle $(\alpha, \mathrm{rad})$, i.e., the displacement lags impressed force, was calculated according to Rao (2011) as:

$$
\alpha=\tan ^{-1} \frac{2 \varepsilon\left(\frac{\omega}{\omega_{n}}\right)}{\left[1-\varepsilon\left(\frac{\omega}{\omega_{n}}\right)^{2}\right]}
$$

Where:

$\varepsilon$ is the damping ratio $(=0.168)$;

$\omega$ is the maximum applied frequency $(=27 \mathrm{~Hz})$, and

$\omega_{\mathrm{n}}$ is the natural frequency of the olive branch (62.6 $\mathrm{Hz})$. Accordingly, the phase angle $(\alpha)$ was estimated to be $0.1484 \mathrm{rad}$.

Regarding the determination of the mechanical properties of the wood using the resonance vibration method, Vobolis \& Aleksiejunas (2002) described the wood as polymeric material and placed them into the category of visco-elastic materials. Hence, the wood's mechanical properties were defined in terms of elastic solids and viscous liquids (Fig. 5).

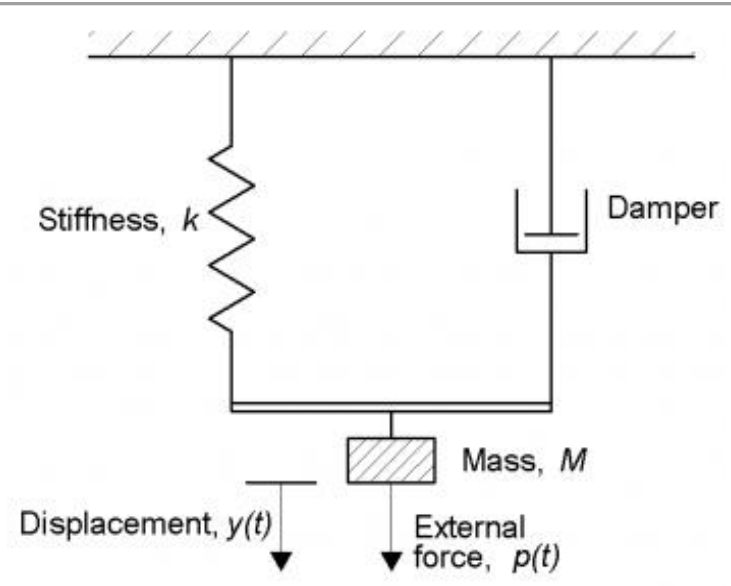

FIGURE 5. Olive branch, spring-mass-damper, model.

The olive branch was considered as a stiffness member with internal damping (Fig. 5). Thus, the externally applied force to the branch is equivalent to the summation of the spring force, movement force, and damping force (spring/mass/damper system). Thus, the force balance of the branch can be expressed by:

$$
-K x-C \frac{d x}{d t}+m \frac{d^{2} r}{d t^{2}} \cos \omega t=M \frac{d^{2} x}{d t^{2}}
$$

Where:

$x$ is the instantaneous displacement of the branch from its equilibrium position (m);

$C$ is the coefficient of viscous damping $\left(\mathrm{N} \mathrm{m} \mathrm{s}^{-1}\right)$;

$M$ is the branch mass $(\mathrm{kg})$;

$\omega$ is the frequency, and

$r$ is the radius of the circular disk.

Substituting $\left(d^{2} r / d t^{2}\right)$ by $\left(r \omega^{2}\right)$, [eq. (6)] can be expressed as:

$$
m r \omega^{2} \cos \omega t=M \frac{d^{2} x}{d t^{2}}+K x+C \frac{d x}{d t}
$$

The instantaneous displacement of the branch $(x)$ can be expressed by:

$$
x=\frac{S}{2} \cos (\omega t-\alpha)
$$

Where:

$S$ is the maximum applied stroke. The first and second differentiation of the displacement, $x$, is given by:

$$
\begin{aligned}
& \frac{d x}{d t}=-\frac{S}{2} \omega \sin (\omega t-\alpha) \\
& \frac{d^{2} x}{d t^{2}}=-\frac{S}{2} \omega^{2} \cos (\omega t-\alpha)
\end{aligned}
$$

Accordingly, the power $(P=$ force $\times$ speed $)$, required to vibrate the system can be expressed as: 


$$
P=\left(m r \omega^{2} \cos \omega t\right)\left[-\frac{S}{2} \omega \sin (\omega t-\alpha)\right]
$$

The maximum required power $\left(P_{\max }\right)$, in Watt, was obtained by differentiating [eq. (11)].

$P_{\max }=\frac{m r \omega^{3} S}{4}( \pm 1-\sin \alpha)$

Substituting the values of $m, r, \omega, S$, and $\alpha$ into [eq. (12)] gives the value of maximum required power (1024.58 W). A gasoline engine of $1100 \mathrm{~W}$ was selected. The different components of the manufactured harvester (air compressor, air tank, gasoline engine, power transmission system, pressure relief valve, and chassis) were assembled in a compacted size and illustrated in Fig. (6) and listed in Table (2).

\section{Experimental measurements and evaluation criteria}

Shemlali variety olive branches were shaken using the developed pneumatic harvester. The branches were chosen at a critical stage of maturity (containing full mature stage, halfripe, and full-ripe olive fruits). Plastic nets were fixed on a stand to collect the removed fruits. The shaker was attached to each branch at a distance of $0.65 \mathrm{~m}$ from the trunk of the tree (i.e., $\approx 30-40 \%$ of the limb length) as recommended by Erdoğan et al. (2003) .After shaking each branch, the fruits removed by the shaker were collected and counted.

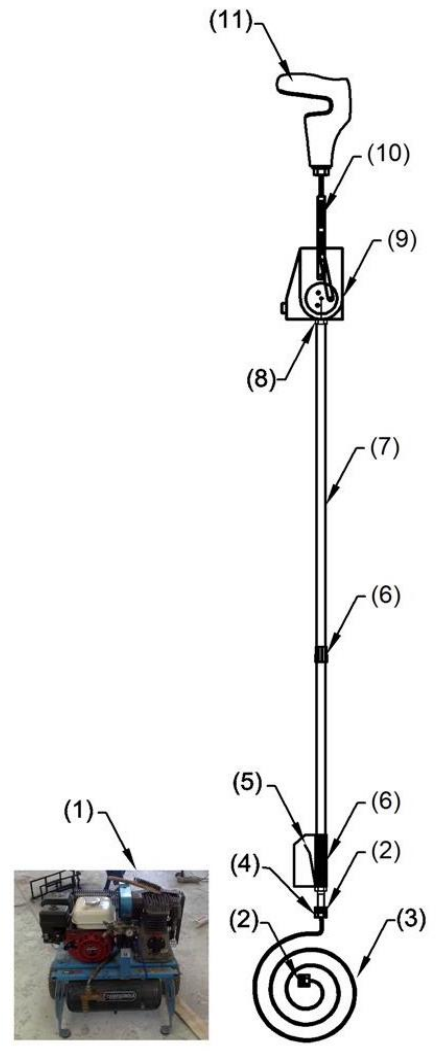

FIGURE 6. Pneumatic olive harvester components.

TABLE 2. The components of pneumatic olive harvester.

\begin{tabular}{ccl|ccl}
\hline Item & Quantity & Title/Name & Item & Quantity & \multicolumn{2}{c}{ Title/Name } \\
\hline$(1)$ & 1 & Air compressor and gasoline engine & $(7)$ & 1 & Main tube \\
$(2)$ & 2 & Coupler set with plug connection & $(8)$ & 1 & Fitting connector \\
$(3)$ & 1 & Air hose, 10-m length & $(9)$ & 1 & Vibrating unit \\
$(4)$ & 1 & Plug set with 1/4" connector & $(10)$ & 1 & Shaking arm \\
$(5)$ & 1 & Control valve & & & Lim clamp \\
$(6)$ & 2 & Hand arm & & \\
\hline
\end{tabular}

\section{Experimental procedure}

\section{Frequency}

Four frequencies were applied for testing the harvester (i.e., 21, 23, 25, and $27 \mathrm{~Hz}$ ) according to (Leone et al., 2015). These frequencies were obtained by regulating the air pressure; they were measured using a hand-held digital photo/contact tachometer and listed in Table (3).
TABLE 3. Tested frequencies $(\mathrm{Hz})$ corresponding to air pressure (bar).

\begin{tabular}{cc}
\hline Air pressure, $($ bar $)$ & Frequency, $(\mathrm{Hz})$ \\
\hline 5.1 & 21 \\
5.5 & 23 \\
5.9 & 25 \\
6.3 & 27 \\
\hline
\end{tabular}




\section{Shaking stroke}

Three strokes of 50,60, and $70 \mathrm{~mm}$ were tested as recommended by Aiello et al. (2019).

\section{Chemical abscission treatment}

The abscission chemical (Ethrel) at a concentration of $12.5 \mathrm{ml} \mathrm{l}^{-1}$ (recommended by Sessiz \& Ozcan 2006) was sprayed after harvest the olive trees by two weeks.

\section{Evaluation criteria}

\section{Machine productivity}

The productivity $(P m)$, in $\mathrm{kg} \mathrm{h}^{-1}$, of the developed harvester was calculated as follows:

$$
P_{m}=\frac{W}{T}
$$

Where:

$W$ depicts the weight of the harvested fruits $(\mathrm{kg})$, and

$T$ is the total operating time (h).

\section{Fruit removal}

The fruit removal percentage $(F R, \%)$ was calculated according to $\mathrm{Pu}$ et al. (2018) as follows:

$$
F R=\frac{M 1}{M 1+M 2} \times 100
$$

Where:

$M 1$ is the weight of the harvested olive fruits $(\mathrm{kg}$ tree $\left.^{-1}\right)$, and

$M 2$ is the weight of the olive fruits remained on the tree $\left(\mathrm{kg}\right.$ tree $\left.{ }^{-1}\right)$.

\section{Fruit damage}

Fruit damage percentage $(F D, \%)$ was calculated according to Khdair et al. (2018) as follows:

$$
F D=\frac{W d}{W t} \times 100
$$

Where:

$W d$ is the weight of injured harvested fruits $(\mathrm{kg})$, and $W t$ is the total weight of harvested fruits $(\mathrm{kg})$.
Limb damage depth (LD) at point of contact with machine clamp

The damage of the tree limb at the point of contact with the clamp of tree shaking machine was determined in terms of the bruise depth at the limb damage. This value of LD is measured by Vernier caliper.

\section{Breakage of shaken limb}

The breakage of shaken limb was measured in terms of the length of the breakage zone using a Vernier caliper.

\section{Consumed energy (CE)}

The $C E$ depicts the specific power per unit capacity (W h kg-1), calculated by:

$$
C E=R P / P m
$$

Where:

$R P$ is the required power to operate the harvesting system $(1100 \mathrm{~W})$, and

$P_{m}$ is the machine productivity $\left(\mathrm{kg} \mathrm{h}^{-1}\right)$.

\section{Statistical analyses}

Standard Error (SE) was applied to detect significant differences among treatment means. A multiple linear regression model was used for determining the relative contribution of related components to the dependent variable $(\mathrm{Y})$.

\section{RESULTS AND DISCUSSION}

\section{Physical and mechanical properties of Shemlali olives fruit-stem system}

The average values of the olive fruit length, fruit diameter, bulk density, effective firmness, stem length, fruit mass, detachment force, and the ratio between detachment force and fruit mass $\left(R_{F m}\right)$ are listed in Table (4). It is clear that higher values of $\mathrm{CV}$ (more than $8 \%$ ) were accompanied with the properties of fruit length, fruit diameter, fruit mass, and fruit detachment force, while lower values of CV (less than $6 \%$ ) were accompanied with the bulk density, effective firmness, stem length, and fruit detachment force to mass ratio of olive fruit. All properties of fruit-stem system were

\begin{tabular}{|c|c|c|c|c|c|c|}
\hline \multirow{2}{*}{ Property } & \multicolumn{2}{|c|}{ Full mature stage } & \multicolumn{2}{|l|}{ Half-ripe } & \multicolumn{2}{|l|}{ Full-ripe } \\
\hline & Mean value & $\mathrm{CV}^{(\mathrm{b})}$ & Mean value & $\mathrm{CV}^{(\mathrm{b})}$ & Mean value & $\mathrm{CV}^{(\mathrm{b})}$ \\
\hline Fruit length, mm & $16.22 \pm 0.24^{\mathrm{a}}$ & 14.66 & $16.32 \pm 0.18$ & 11.17 & $16.45 \pm 0.22$ & 15.32 \\
\hline Fruit diameter, mm & $11.00 \pm 0.09$ & 8.45 & $11.60 \pm 0.13$ & 11.21 & $13.05 \pm 0.14$ & 10.75 \\
\hline Bulk density, $\mathrm{g} \mathrm{cm}^{-3}$ & $1.73 \pm 0.00$ & 2.02 & $1.00 \pm 0.00$ & 3.87 & $0.99 \pm 0.00$ & 3.33 \\
\hline Effective firmness, MPa & $0.51 \pm 0.00$ & 2.67 & $0.21 \pm 0.00$ & 2.50 & $0.07 \pm 0.00$ & 3.83 \\
\hline Stem length, mm & $148.0 \pm 0.25$ & 1.67 & $148.5 \pm 0.49$ & 3.32 & $149.5 \pm 0.47$ & 3.15 \\
\hline Fruit mass, $\mathrm{g}$ & $1.40 \pm 0.02$ & 11.46 & $1.48 \pm 0.03$ & 14.65 & $1.62 \pm 0.02$ & 13.54 \\
\hline Detachment force, $\mathrm{N}$ & $3.14 \pm 0.04$ & 12.67 & $3.00 \pm 0.03$ & 11.59 & $2.44 \pm 0.04$ & 14.66 \\
\hline$R_{F m}, \mathrm{~N} \mathrm{~g}^{-1}$ & $2.26 \pm 0.01$ & 5.21 & $2.12 \pm 0.00$ & 3.95 & $1.52 \pm 0.00$ & 4.22 \\
\hline
\end{tabular}
significant among the three maturity stages except fruit length and stem length.

TABLE 4. Physical and mechanical properties of Shemlali olive fruit-stem system.

${ }^{a}$ Standard Error (SE); difference between two means $\geq \mathrm{SE}$ indicates significant difference.

${ }^{\mathrm{b}} \mathrm{CV}$ Coefficient of variation (Standard deviation divided by mean value). 


\section{Machine productivity $(P m)$}

The effect of the frequency and stroke with and without chemical abscission on the machine productivity are shown in Fig. (7). The machine productivity $(P m)$ was observed to increase by increasing both the frequency and stroke. The $P m$ values were in the range of 79.5-90 $\mathrm{kg} \mathrm{h}^{-1}$ and $46.5-72 \mathrm{~kg} \mathrm{~h}^{-1}$ with and without chemical abscission, respectively. This may be attributed to the increase in the inertia of the olive fruit, which overcomes the detachment force required to separate the fruit. The largest values of $\mathrm{Pm}, 72 \mathrm{~kg} \mathrm{~h}^{-1}$ and $90 \mathrm{~kg} \mathrm{~h}^{-1}$, occurred at $27 \mathrm{~Hz}$ frequency and $70 \mathrm{~mm}$ stroke with and without chemical abscission, respectively. This observation could be attributed to the above-mentioned theory. Also, fig. (7) showed that the use of chemical abscission resulted in an increase of the machine productivity for all frequencies and stroke levels. This may be due to the formation of an abscission zone in the fruit stem as a result of the chemical treatment, which facilitates fruit separation and thus increases the machine productivity. These results were in agreement with the findings obtained by Sessiz \& Ozcan (2006). Thus, the highest $\mathrm{Pm}$ occurred at $27 \mathrm{~Hz}$ frequency and $60 \mathrm{~mm}$ or 70 $\mathrm{mm}$ stroke.

The multiple regression analysis showed that there was a significant correlation between the frequency $(\omega)$, stroke $(\boldsymbol{S})$, and machine productivity $(\boldsymbol{P m})$ for both cases with and without chemical abscission. Further, a multiple regression analysis yielded polynomial eqs (17) and (18) as follows:

For the use of chemical abscission:

$$
\begin{aligned}
& P m=1.250 \omega+0.144 S-48.208 \\
& \mathrm{R}^{2}=0.773
\end{aligned}
$$

For the absence of chemical abscission:

$$
\begin{aligned}
& P m=3.740 \omega+0.178 S-39.033 \\
& \mathrm{R}^{2}=0.864
\end{aligned}
$$

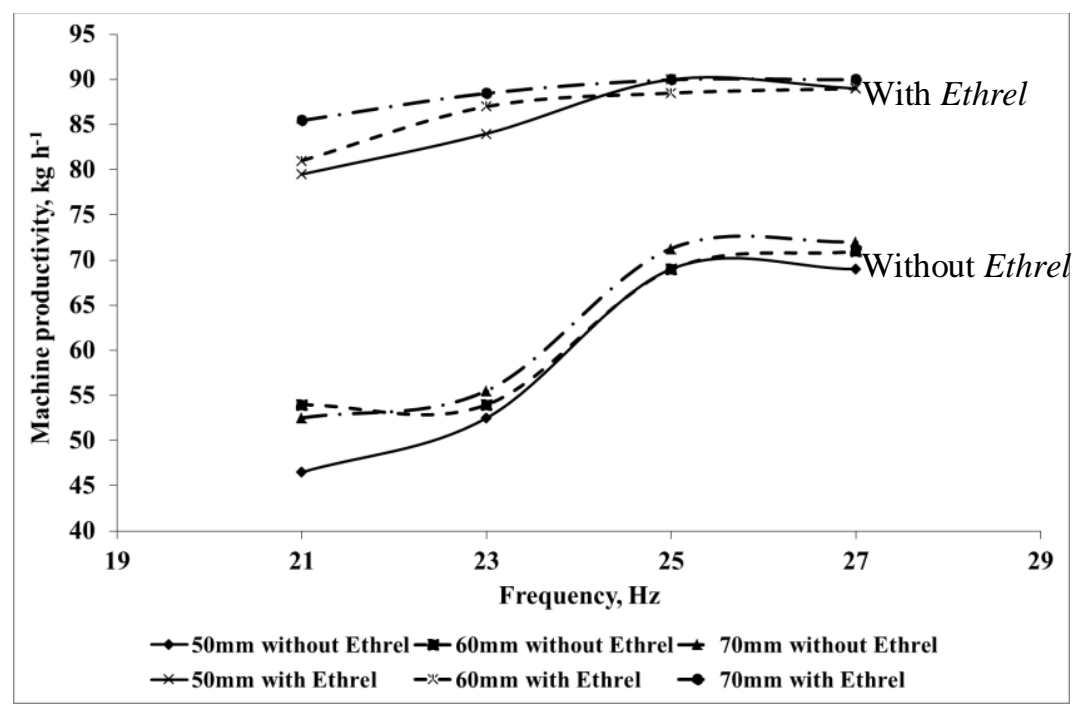

FIGURE 7. Effect of frequency and stroke on machine productivity with and without the use of chemical abscission.

\section{Fruit removal (FR)}

The average values of olive fruit removal $(F R)$ are shown in Table (5). From Table (5), it is evident that the FR values (with and without chemical abscission) increased with increased frequency and stroke. The increase in the frequency from $21 \mathrm{~Hz}$ to $27 \mathrm{~Hz}$ caused an increase in the $F R$ from $52.5 \%$ to $79 \%$ at $60 \mathrm{~mm}$ stroke for the treatment without chemical abscission. The same trend was observed for all other tested strokes. This may be attributed to increase in the centrifugal force due to the increase in the limb frequency, which enhances the fruit removal. For the treatment with chemical abscission, the percentage of fruit removal increased from $88.5 \%$ to $95.5 \%$ as the stroke increased from $50 \mathrm{~mm}$ to $70 \mathrm{~mm}$ at a frequency of $23 \mathrm{~Hz}$. The same trend was found for all other tested frequencies. The highest values of $F R, 81 \%$ and $99.6 \%$, occurred at 27 $\mathrm{Hz}$ frequency and $60 \mathrm{~mm}$ or $70 \mathrm{~mm}$ stroke without chemical abscission. This may be attributed to the decrease in the detachment force in the case of chemical abscission. The results were in agreement with the findings obtained by Sessiz \& Ozcan (2006) and Khdair et al. (2018). The multiple regression analysis showed that there was a significant correlation between the frequency $(\omega)$, stroke $(S)$, and olive-fruit removal $(F R)$ for both treatments with and without chemical abscission. Further, a multiple regression analysis yielded the following polynomial eqs (19) and (20):

With chemical abscission:

$$
\begin{aligned}
& F R=1.498 \omega+0.199 S-47.757 \\
& \mathrm{R}^{2}=0.746
\end{aligned}
$$

Without chemical abscission:

$$
\begin{aligned}
& F R=4.705 \omega+0.280 S-62.712 \\
& \mathrm{R}^{2}=0.847
\end{aligned}
$$

From Fig. (10) and Table (5), it is deduced that the highest $\boldsymbol{P} \boldsymbol{m}$ and $\boldsymbol{F R}$ were performed at $27 \mathrm{~Hz}$ frequency and $60 \mathrm{~mm}$ or $70 \mathrm{~mm}$ stroke. 
TABLE 5. Effect of frequency and stroke on fruit removal with and without using chemical abscission.

\begin{tabular}{lccccc}
\hline Chemical & \multirow{2}{*}{\begin{tabular}{c}
\multirow{2}{*}{ abscission } \\
Stroke, $\mathrm{mm}$
\end{tabular}} & \multicolumn{5}{c}{ Frequency, Hz } \\
\cline { 2 - 6 } Without & 50 & $51.3 \pm 1.47^{\mathrm{a}}$ & $53.7 \pm 1.34$ & $77.1 \pm 1.15$ & $77.0 \pm 1.87$ \\
Ethrel & 60 & $52.5 \pm 2.14$ & $55.0 \pm 1.34$ & $77.0 \pm 1.15$ & $79.0 \pm 2.33$ \\
& 70 & $60.1 \pm 2.76$ & $61.4 \pm 1.89$ & $79.0 \pm 1.37$ & $81.0 \pm 1.67$ \\
\hline \multirow{2}{*}{ With } & 50 & $86.3 \pm 0.64$ & $88.5 \pm 0.12$ & $98.7 \pm 0.15$ & $99.1 \pm 0.01$ \\
Ethrel & 60 & $92.0 \pm 0.17$ & $96.0 \pm 0.22$ & $99.0 \pm 0.19$ & $99.6 \pm 0.00$ \\
& 70 & $95.0 \pm 0.82$ & $95.5 \pm 1.10$ & $99.0 \pm 0.19$ & $99.0 \pm 0.12$ \\
\hline
\end{tabular}

${ }^{a}$ Standard deviation (SD); difference between two means $\geq$ SD indicates significant difference.

\section{Fruit damage (FD)}

The average values of olive fruit damage $(F D)$ are presented in Table (6). The $F D$ values were not affected by the frequency and stroke and ranged from $2.5 \%$ to $3.5 \%$ for all tested frequencies and stroke ranges. The low $F D$ values may be attributed to the mechanism of the machine operation.
The detachment occurs in the stem, and there is no direct contact with the fruit itself. Further, the fruits are collected in an above ground net, thus minimizing the damage caused by the fruit hitting the ground. Multiple regression analysis showed that there was no significant relation between the frequency $(\omega)$, stroke $(S)$, and fruit damage $(F D)$ for both the cases with and without chemical abscission.

TABLE 6. Effect of frequency and stroke on fruit damage (\%) with and without chemical abscission.

\begin{tabular}{lllllll}
\hline & \multicolumn{3}{c}{ Stroke, mm } & \multicolumn{3}{c}{ With spraying Ethrel } \\
\cline { 2 - 7 } & 50 & Without spraying Ethrel & & 50 & 60 & 70 \\
\hline $\mathbf{2 1}$ & 2.8 & 2.5 & 3.2 & 2.6 & 2.8 & 3.0 \\
$\mathbf{2 3}$ & 2.5 & 2.5 & 3.0 & 3.0 & 2.9 & 3.0 \\
$\mathbf{2 5}$ & 2.6 & 3.0 & 3.1 & 3.5 & 3.0 & 3.0 \\
$\mathbf{2 7}$ & 3.0 & 3.0 & 3.4 & 3.1 & 3.0 & 3.5 \\
\hline
\end{tabular}

\section{Limb damage depth $(L D)$ at point of contact with shaking machine clamp}

The values of the limb damage $(L D)$ at the point of contact with the clamp of the shaking machine (when the developed machine operates without chemical abscission) are shown in Fig. (8). The maximum value of limb damage depth, $2.7 \mathrm{~mm}$, was found at a stroke of $70 \mathrm{~mm}$ and frequency of $27 \mathrm{~Hz}$. Fig. (8) shows that the limb damage depth at point of contact with developed machine clamp decreased by increasing the shaking stroke above $60 \mathrm{~mm}$. However, there were no effects of the tested frequencies (21 to $27 \mathrm{~Hz}$ ) at the $L D$ damage above one $\mathrm{mm}$. Thus, the machine can be operated safely at frequencies from $21 \mathrm{~Hz}$ to $27 \mathrm{~Hz}$ and at the strokes from $50 \mathrm{~mm}$ to $60 \mathrm{~mm}$. The stroke can also be increased from $60 \mathrm{~mm}$ to $70 \mathrm{~mm}$, provided that the frequency does not exceed $23 \mathrm{~Hz}$. A similar trend was found when the machine operated after spraying the olive trees with Ethrel (chemical abscission) at a concentration of $12.5 \mathrm{ml} \mathrm{l}^{-1}$.

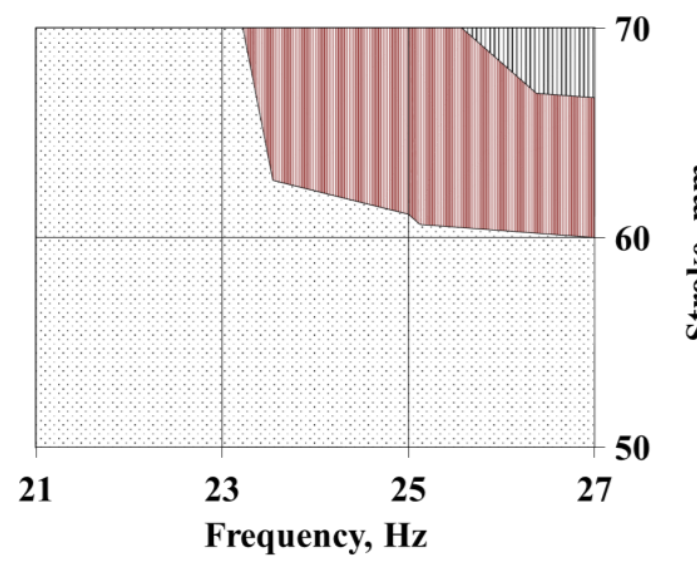

$$
\square 0-1 \quad \square 1-2 \quad \square 2-3
$$

FIGURE 8. Effect of frequency and stroke on limb damage depth at point of contact with developed machine clamp. 
The limb damage $(L D)$ that resulting from operating the developed machine is like to girdling treatments that were applied by removing a narrow ring of the bark (maximum depth $1 \mathrm{~mm}$ ) from base of branching zone. Girdling process regulates plant growth and photosynthesis for olive tree. Limb damage depth and griddling may positively affect ethylene which stimulates the induction of the floral buds and improve flowering in the following season. An increase in flower initiation following possible phloem blockage due to vibrating action, is usually evident in the season following treatment (Annabi, et al., 2019).

\section{Breakage of shaken limb $(L B)$}

The values of limb breakage $(L B)$ in $\mathrm{mm}$ (when the developed machine operated without chemical abscission) are shown in Fig. (9). From Fig. (9) it's clear that the maximum value of limb breakage, $6.9 \mathrm{~mm}$, occurred at stroke $70 \mathrm{~mm}$ and frequency $27 \mathrm{~Hz}$. Also, Fig. (9) shows that, by increasing the stroke over $60 \mathrm{~mm}$ and frequency over about $23 \mathrm{~Hz}$, the limb breakage was increased over one $\mathrm{mm}$. But there were no effects of the tested frequencies on $L B$ over one mm. Thus, the developed machine can be operated safely at frequencies from 21 to $27 \mathrm{~Hz}$ and the strokes from 50 to $60 \mathrm{~mm}$. The same trend was found when the machine operated after spraying the olive trees with Ethrel (chemical abscission) at a concentration of $12.5 \mathrm{ml} \mathrm{l}^{-1}$.

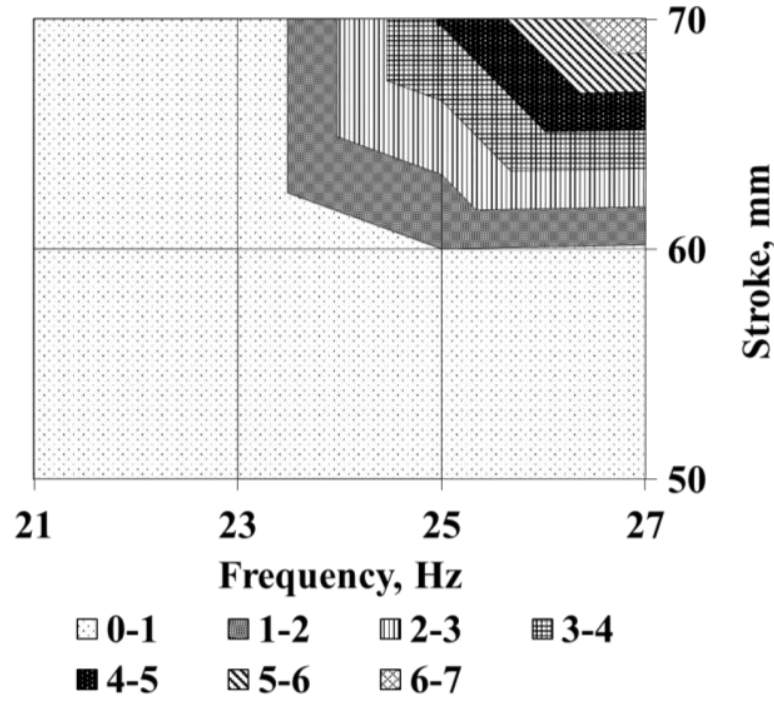

FIGURE 9. Effect of frequency and stroke on limb breakage.

\section{Consumed energy $(C E)$}

The average values of the consumed energy $(\boldsymbol{C E})$ at different frequency and stroke levels (with and without application of abscission chemical) are presented in Fig. (10).

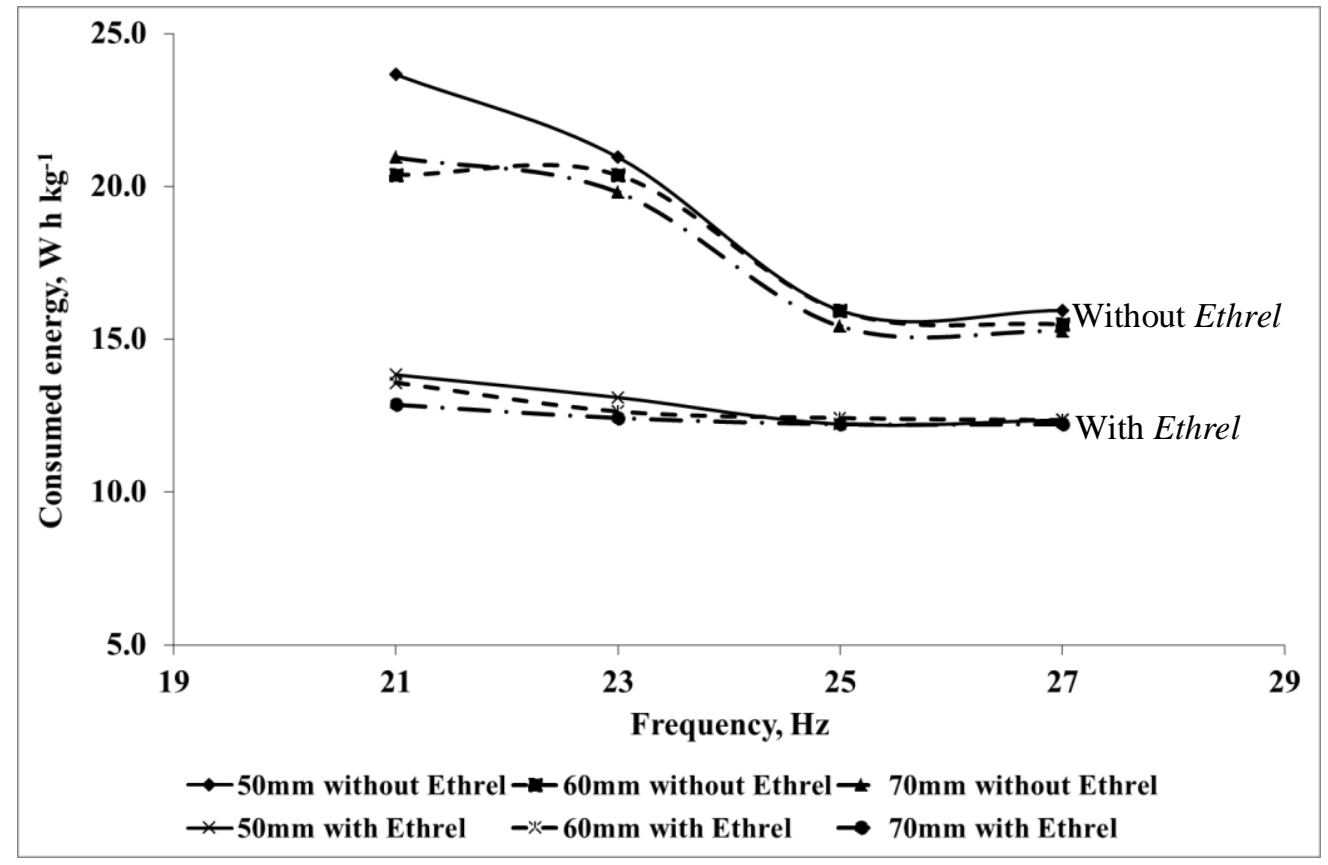

FIGURE 10. Effect of frequency and stroke on consumed energy with and without chemical abscission.

Increasing the frequency from $21 \mathrm{~Hz}$ to $27 \mathrm{~Hz}$ decreased the consumed energy by $51.69 \%$, and a further $8.82 \%$ with chemical abscission at stroke of $60 \mathrm{~mm}$. This may be attributed to an increase in productivity by augmentation of the frequency. Results show that applying the abscission chemical decreased the consumed energy by $37.37 \%$ at a frequency of $23 \mathrm{~Hz}$ and stroke length of $70 \mathrm{~mm}$ compared to without chemical abscission. This also may be attributed to the increase of machine productivity with the abscission chemical.

The results from this paper indicated that the maximum fruit removal \& machine productivity with minimum fruits \& limb damage was performed at $27 \mathrm{~Hz}$ frequency and $60 \mathrm{~mm}$ or $70 \mathrm{~mm}$ stroke. These results are similar to those found by Polat et al. (2017), who reported that the fruit removal was $93.27 \%$ at a frequency of $40 \mathrm{~Hz}$ and $20 \mathrm{~mm}$ amplitude.

\section{Cost analysis}

The olive harvesting cost involved for the developed machine was calculated as follows:

\section{Fixed cost}

The machine-related fixed costs included depreciation, interest, taxes, housing and insurance. Assuming a machine life expectancy of ten years, an 
interest rate of $10 \%$ and a machine salvage rate of $10 \%$ of the machine price (cost) of $\$ 1500$, the annual capital consumption (CC), which included the depreciation and the interest costs, was estimated at $25 \%$ of the machine cost (Hunt, 1983). Therefore, the annual CC for the developed machine was estimated at $\$ 375$ With the assumption of 200 operating hours per year, the depreciation and interest costs were calculated at $\$ 1.87 \mathrm{~h}^{-1}$. The remaining three elements of the fixed costs (interest, taxes and housing) were, annually, assumed to be $2 \%$ of the machine cost (Hunt, 1983), which was calculated at $\$ 30 \mathrm{y}^{-1}$, hence $\$ 0.15 \mathrm{~h}^{-1}$. The fixed cost was determined at $\$ 2.02 \mathrm{~h}^{-1}$.

\section{Operation (variable) cost}

The operational costs included the cost of labor, fuel cost, repair and maintenance. The labor cost was calculated based on three laborers were required to properly operate the machine and collect the harvested fruits. This cost was estimated at $\$ 6.5$ day $^{-1}\left(8 \mathrm{~h} \mathrm{day}^{-1}\right)$, hence the labor cost was calculated at $\$ 0.81 \mathrm{~h}^{-1}$. The fuel cost of the machine was determined to be $\$ 0.39 \mathrm{~h}^{-1}$. However, the cost of repair and maintenance was estimated at $2 \%$ of the machine cost per 100 hours of operation (Hunt, 1983), which was calculated at $\$ 0.3 \mathrm{~h}^{-1}$. Therefore, the operation (variable) cost was determined at $\$ 1.5 \mathrm{~h}^{-1}$. Then the total machine cost was estimated at $\$ 3.52 \mathrm{~h}^{-1}$.

The olive harvesting cost $\left(\$ \mathrm{~kg}^{-1}\right)$ is defined as the machine cost $\left(\$ \mathrm{~h}^{-1}\right)$ divided by the machine productivity $\left(\mathrm{kg} \mathrm{h}^{-1}\right)$. The average value of olive harvesting cost in case of applying the abscission chemical was $\$ 0.041 \mathrm{~kg}^{-1}$ compared to $\$ 0,12 \mathrm{~kg}^{-1}$ when the abscission chemical is not used.

\section{CONCLUSIONS}

The following conclusions are made from this investigation:

1. Spraying of olive trees before harvesting with Ethrel led to an increase both in machine productivity and fruit removal efficiency, as well as a decrease in consumed energy

2. Maximum machine productivities, $72 \mathrm{~kg} \mathrm{~h}^{-1}$ and $90 \mathrm{~kg} \mathrm{~h}^{-1}$, were performed at $27 \mathrm{~Hz}$ frequency and $60 \mathrm{~mm}$ or $70 \mathrm{~mm}$ stroke with and without chemical abscission for olive fruits of the Shemlali variety.

3. Highest values of fruit removal, 81 and $99.6 \%$, were performed at $27 \mathrm{~Hz}$ frequency and $60 \mathrm{~mm}$ or $70 \mathrm{~mm}$ stroke without and with chemical abscission respectively.

4. Olive fruit damage is not affected by the frequency and stroke range. The damage ranged between $2.5 \%$ and $3.5 \%$ for all tested frequencies and strokes.

5. The minimum value, $\leq$ one $\mathrm{mm}$, of limb damage depth at the point of contact with the clamp of the shaking machine was found at frequencies from 23 to $27 \mathrm{~Hz}$ and strokes from 50 to $60 \mathrm{~mm}$.

6. The minimum value of limbs breakage, $\leq$ one $\mathrm{mm}$, was likewise found at frequencies from 23 to $27 \mathrm{~Hz}$ and strokes ranged from $50 \mathrm{~mm}$ to $60 \mathrm{~mm}$.

7. The minimum values of consumed energy were achieved at $27 \mathrm{~Hz}$ frequency and $60 \mathrm{~mm}$ or $70 \mathrm{~mm}$ stroke with and without chemical abscission.
Therefore, the suitable parameters for the developed machine operation with regard to the machine productivity, fruit removal, fruit damage, limb damage at the point of contact with clamp of shaking machine, breakage of shaken limbs, and consumed energy were found to be at $27 \mathrm{~Hz}$ frequency and $60 \mathrm{~mm}$ stroke.

\section{ACKNOWLEDGEMENTS}

The authors thank the Deanship of Scientific Research and RSSU at King Saud University for their technical support.

\section{REFERENCES}

Aiello G, Vallone M, Catania P (2019) Optimising the efficiency of olive harvesting considering operator safety. Biosystems Engineering. 185:15-24 DOI: https://doi.org/10.1016/j.biosystemseng.2019.02.016

Alzoheiry A, Ghonimy MI, Abd El Rahman E, Abdelwahab O, Hassan A (2020) Improving olive mechanical harvesting using appropriate natural frequency. Journal of Agricultural Engineering 51(3): 148154. DOI: https://doi.org/10.4081/jae.2020.1057

Annabi K, Laaribi I, Gouta H, Laabidi F, Mechri B, Ajmi L, Zouari I, Muscolo A, Panuccio MR, Mezghani MA (2019) Protein content, antioxidant activity, carbohydrates and photosynthesis in leaves of girdled stems of four olive cultivars, Scientia Horticulturae 256: 108551. DOI: https://doi.org/10.1016/j.scienta.2019.108551

Erdoğan D, Güner M, Dursun E, Gezer I (2003)

Mechanical harvesting of apricots. Biosystems

Engineering 85:19-28. DOI:

https://doi.org/10.1016/S1537-5110(03)00024-2

FAOSTAT (2018) FAO Statistical Yearbook. Agricultural production. Available : http://www.fao.org/faostat. Accessed Aug, 2018.

Ghonimy MI, Ibrahim MM, Abd El Rahman EN, Hassan AM (2020) Development of olive harvesting machine for smallholdings. Plant Archives 20(2): 3576-3583. DOI: https://doi.org/10.21608/mjae.2018.95541

Guzmán E, Baeten V, Pierna JAF, García-Mesa JA (2013) Determination of the olive maturity index of intact fruits using image analysis. Journal of food science and technology 52(3): 1462-1470. DOI: https://doi.org/10.1007/s13197-013-1123-7.

Hunt D. (1983) Farm power and machinery management. Lowa, Iowa State Univ, 8 ed.

Ibrahim MM (2018) Development of an electrical handheld olive harvester. Misr Journal Agricultural Engineering 35(3):827 - 846.

Khdair AI, Abu-Rumman, G, Khdair SI (2018) Evaluation the mechanical harvesting efficiency of olive with the application of fruit loosening spray. Agricultural Engineering International. CIGR Journal 20(4):69-75. 
Leone A, Romaniello R, Tamborrino A, Catalano P, Peri $G$ (2015) Identification of vibration frequency, acceleration, and duration for efficient olive harvesting using a trunk shaker. Transactions of the ASABE 58(1):18. DOI: https://doi.org/10.13031/trans.58.10608

Nasini L, Proietti P (2014) Olive Harvesting, Chapter 8 in the Extra-Virgin Olive Oil Handbook. John Wiley \& Sons Ltd, Chichester, West Sussex, UK.

Peterson DL, Whiting MD, Wolford DD (2003) Freshmarket quality tree fruit harvester, Part 1: sweet cherry. Applied Engineering in Agriculture19(5): 539-543.

DOI: https://doi.org/10.13031/2013.15313.

Polat R, Güner M, Erdoğan D, Gezer İ, Atay Ü, Aktaş T (2017) Determination of optimum shaking frequency and amplitude of prototype body shaker used for mechanical harvesting of pistachio. In: International Symposium on Agricultural Engineering, Actual Tasks on Agricultural Engineering. Opatija, University of Zagreb, Faculty of Agriculture, Proceedings...

Pu YJ, Toudeshki A, Ehsani R, Yang FZ, Abdulridha $J$ (2018) Selection and experimental evaluation of shaking rods of canopy shaker to reduce tree damage for citrus mechanical harvesting. International Journal of Agricultural \& Biological Engineering 11(2): 48-54.

Rao SS (2011) Mechanical vibrations. Pearson, Education Prentice Hall, 5 ed.
Sessiz A, Ozcan MT (2006) Olive removal with pneumatic branch shaker and abscission chemical. Journal of Food Engineering 76: 148-153. DOI:

https://doi.org/10.1016/j.jfoodeng.2005.05.002

Sibbett GS, Ferguson L, Coviello JL, Lindstrand M (2005) Olive Production Manual. 2ed Edition. University of California, Agriculture and Natural Resources, p33-53.

Sola-Guirado RR, Jimenez-Jimenez F, Blanco-Roldan GL, Castro-Garcia S, Castillo-Ruiz FJ, Gil Ribes JA (2016) Vibration parameters assessment to develop a continuous lateral canopy shaker for mechanical of traditional olive trees. Spanish Journal of Agricultural Research 14(2): e0204, 10 pages.

DOI: https://doi.org/10.5424/sjar/2016142-7909

Vobolis J, Aleksiejunas M (2002) Investigation of wood mechanical properties by the resonance vibration method. Materials Science 9(1):139-143.

Younis SM, Abdelbary KM, ELMesery SA, Abdelahady AA (2017) Design and evaluation a hand-held machine for olives harvesting. Misr Journal Agricultural of Engineering 34 (1):103-122.

Zhou JL, Zhang Q, Karkee M (2014) Effect of excitation position of a handheld shake,r on fruit removal efficiency and damage in mechanical harvesting of sweet cherry. Bio systems engineering 125: 36-44.

https://doi.org/10.1016/j.biosystemseng.2014.06.016. 